\title{
Scientific Evaluation of Dietary Factors in Cancer
}

\author{
M Waheed Roomi ${ }^{1}$, Aleksandra Niedzwiecki ${ }^{*}$ and Matthias Rath ${ }^{3}$
}

Dr. Rath Research Institute, USA

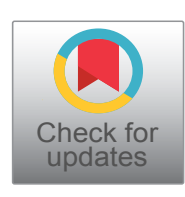

*Corresponding author: Aleksandra Niedzwiecki, Dr. Rath Research Institute, 1260 Memorex Dr, Santa Clara, CA 95050, USA, Tel: 1408-567-5000

\begin{abstract}
Epidemiological and experimental studies suggest that a proper diet and a healthy life style can decrease the risk of cancer by up to $70 \%$. The cancers most closely related to nutrition are breast and endometrial cancers in women and prostate and gastrointestinal cancers in men. The review outlines that many anti-oxidants, vitamins, phytochemicals, and other micronutrients in food have cancer preventing effects, while many food additives, pesticide residues and high consumption of charbroiled meat, nitrites, salt, animal fat and trans fatty acids have been associated with increased cancer risk. Most studies with micronutrients in relation to cancer have been conducted with individual compounds. In contrast, our in vitro and in vivo research utilizing over 50 human cancer cell lines demonstrated better anti-cancer efficacy with a synergistic combination of micronutrients rather than individual compounds. Pleiotropic effects of a nutrient combination have been demonstrated in cancer preventive and also in therapeutic aspects by inhibiting the hallmarks of cancer, including its growth, invasion and metastasis. Dietary approaches to health need to be further explored as being non-toxic, generally well tolerated, and without significant side effects that are commonly associated with conventional chemotherapy and radiation therapy.
\end{abstract}

\section{Keywords}

Diet, Cancer, Lifestyle, Phytochemicals, Nutrient synergy, Pesticides, Food additives

\section{Introduction}

A worldwide surge in the incidence of cancer has become a major public health concern [1,2]. Cancer is the most feared disease, and the second leading cause of death in the United States [3,4]. With 18.5 million new cases and 9.6 million deaths in 2018, cancer is expected to be the number one cause of death by the end of this century, imposing an enormous financial and social burden on patients, their families, and national healthcare systems [3,5]. According to the World Health Organization (WHO) International Agency for Research on Cancer (IARC) the data stress the scope of this health problem as one in five men and one in six women will develop cancer during their lifetime and one in eight men and one in eleven women will die of cancer [6].

The most frequent cancer in men is prostate cancer and in women, it is breast cancer. In both genders, the prevailing are lung and colorectal cancers. Cancers affect more people living in the Western than Eastern countries and the susceptibility to different types of cancer varies. As such, stomach cancer is most common in Japan whereas head and neck cancer and cervical cancer are the most frequent cancers in India. Observational studies suggest that prostate cancer, breast cancer and certain other cancer risks are much lower in the population of South East Asia and Japan compared to America. The development of cancer is a complex process occurring through different stages and virtually all organs and tissues are susceptible to it [7]. Certain types of cancer have been linked to genetic predisposition; however, the main causes of this disease have been mostly related to external factors such as life style, environmental toxins, and diet. This is one of the explanations why national differences in frequency of some types of cancers as mentioned earlier often disappear in respective migrants populations living in the United States due to their exposure to new environmental factors, adaptation to different lifestyle and diets [8-11].

This scientific evaluation reviews and discusses various dietary factors that can affect the development of major types of cancer, both in its preventive and therapeutic aspects. This knowledge is important in 
making informed decisions regarding both individual dietary choices and shaping up health promoting policies.

\section{Major Risk Factors}

It appears that most human cancers can be prevented since they relate to lifestyle, diet, environment, or exposure to occupational chemicals all of which can be modified. Only some cancers have viral or genetic based origins. As such, certain types of cancers, including lymphoma, leukemia, liver and cervical cancers have been linked to the viruses, namely Epstein-Barr virus, HTLV, hepatitis B and C, and human papilloma virus [12]. Genetics has been associated with about $5-10 \%$ of all cancers such as breast and ovarian cancers (BRCA1 and BRCA2 mutations) colorectal (MLH1 and MSH2 mutations), and prostate cancer (parental mutation on chromosome 23 [12-14]. However, the presence of a mutated gene is not the only factor and does not assure that cancer will develop.

A surge of cancer cases observed in recent decades have been largely related to human activities ranging from individual life style changes to a global environmental impact. These factors play a role in common cancers affecting human populations not only in the industrialized countries but also in the developing world [15]. To this extent many cancer studies concluded that diet, smoking, obesity, betel nut use, overexposure to sun, lack of physical activity and alcohol consumption increase cancer risk. Growing consumption of highly processed food as well as expansion of commercial agriculture and animal husbandry contributed to significant changes in the nutritional value of food. Today, food consumed by large populations contains a variety of carcinogenic and mutagenic substances. They include pesticides residues, food colorants and additives, chemical components used in food processing and preservation [16]. These in addition to the exposure to multitude toxins found in air, water and soil could damage the body cells facilitating malignant transformations.

It has been known that certain occupations are linked to increased risk of certain cancers, with the most common occupational cancer types such as lung (up to $13 \%$ ), bladder (up to 19\%), and mesothelioma (up to 90\%) [17]. In many cases, it takes decades of exposure to carcinogens for the disease to surface. Among many high risk professions, the agricultural workers exposed to engine exhaust, pesticides, fertilizers, and other elements have high incidents of lymphoma, leukemia, and several other cancers. Recently, a California farmer prevailed in a law suit against Monsanto (now Bayer) challenging the development of his leukemia cancer to glyphosate contained in Round-up weed killer he had used for many years [18]. Construction workers, car mechanics, and miners are exposed to asbestos causing mesothelioma. In addition, underground workers are more likely to come in contact with uranium and radon, which can lead to a higher risk of cancer. It has been proven that even living in proximity to mines can lead to a higher risk of developing cancer, including brain cancer, mesothelioma, stomach, thyroid cancer, and more. However, the risk is that much more real for the people who actually work there. More than 13 million people in the United States are exposed to chemicals at work that can be absorbed through the skin, according to the CDC. People who work with dyes and paints, for example, are at a heightened risk for developing bladder cancer, according to the American Cancer Society. Repeated exposure to benzidine, arsenic, and beta-naphthylamine are some chemicals that could lead to cancer with long-term use. In addition to occupation related chemicals exposure some pharmaceutical drugs and therapies (i.e., chemo and radiation therapies) are known to increase a risk and even cause cancer [19-22].

\section{Dietary Aspects Related to Cancer}

The National Academy of Sciences, USA estimates that $60 \%$ of female cancers and $40 \%$ of male cancers are related to nutritional factors [7,23,24]. Among two food sources in the human diet-plants and animal meats-it appears that plant-based diet is more health beneficial and could reduce cancer risk even by $30-40 \%$ $[7,23,25,26]$. For this reason, the American Institute for Cancer Research has developed dietary guidelines for lowering the risk and preventing all types of cancer [7], which recommend the consumption of foods mainly from plant sources with five or more servings of fruits and vegetables daily. In addition, the Guideline stresses the importance of limiting the intake of high-fat food, particularly from animal sources and emphasizes the significance of moderate physical activity, maintaining healthy weight, limited alcohol consumption and avoiding tobacco products.

Health benefits of consumption of colored fruits and vegetables have been related to the fact that they are a rich source of antioxidant nutrients, such as vitamins $A$, $C, E$, carotenoids, lycopene, the trace mineral selenium and many other compounds which can protect the body's cells against damage, slow down the malignant process and even reverse it [27-29]. In addition, all plants also contain numerous phytochemicals, such as indoles, isoflavones, terpenes, phenolic acids, carnosol, polyphenols and a component in green tea known as epigallocatechin gallate (EGCG). These compounds appear to be protective against various cancers based on numerous in vitro and animal studies which provide evidence for their potential biochemical and molecular mechanisms of actions [30]. Also, observational studies in human populations support a relationship between a nutrient and a cancer outcome. However, a rather limited number of randomized controlled studies with individual compounds conducted so far were not 
always in favor of anti-cancer efficacy of some individual micronutrients or plant extracts consumed in a form of supplements [31,32]. However, these studies were using different doses of individual components which originated from different manufacturing sources, and also in arbitrary combined formulations therefore they could not lead to definite conclusions. Certainly, more adequately designed and powered clinical trials are needed to address this important aspect. The anti-cancer effects of whole plants may be based on synergistic interactions of their numerous components, as well as the presence of still unidentified beneficial micronutrients or biological compounds, such as dietary fibers which have shown to benefit in preventing colorectal and other cancers $[33,34]$.

A proper diet is important not only in cancer prevention, but also in cancer therapy. Numerous studies indicate that malignancy is accompanied by various micronutrient deficiencies and as such, cancer patients have special nutritional needs. This particularly applies to cancer patients undergoing radiation and/or chemotherapy [35-37]. Studies are rather consistent in showing that optimal nutrition and micronutrient supplementation have a positive impact on toleration of these treatments by patients and reducing detrimental side effects [38-40].

\section{Major Types of Cancers Linked to Diet/Dietary Factors}

It has been shown that the incidence of cancer is lower in the Mediterranean region as compared to the US, UK and other European countries [41]. This has been associated with a characteristic diet for this region which is rich in olive oil, fish, vegetables, legumes, unrefined cereal and a moderate use of dairy products. Research has shown that a type of diet or specific individual dietary components play important roles in the prevention and management of specific cancers.

\section{Breast cancer}

Breast cancer is the leading type of cancer among women-at median age of 61 and it accounts for about $26 \%$ of newly diagnosed cases. Since $90-95 \%$ breast cancer cases is attributable to environmental and lifestyle factors-with diet and obesity contributing $\sim 30-35$ and $10-20 \%$, respectively-this provides major opportunities for nutritional prevention and intervention [25]. Several reports suggest that even low consumption of alcoholic beverages may increase the risk of breast cancer while a diet rich in fruits, vegetables (especially from cruciferous family), fish and poultry decreases it $[23,42,43]$.

Obesity also significantly contributes as a risk factor as well as the animal fat intake. The effects of soy food rich in isoflavones which can have estrogen-like effects on the body have been not consistent in respect to breast cancer. A recent meta-analysis summarizing 14 studies showed that patients who consume moderate amounts of soy throughout their life have a lower breast cancer risk [44]. However, several interventional studies using high doses of soy estrogens have shown changes in breast nipple fluid that would predict higher rates of this cancer [45].

Most experts recommend adhering to a moderate intake of isoflavones rather than using their sources as protective foods.

\section{Endometrial cancer}

Endometrial cancer is the third most common type of cancer diagnosed in women. It is mostly caused by excessive and prolonged stimulation of the endometrium lining the uterus by estrogens unopposed by the hormone progesterone. This cancer is the one of the most strongly associated with obesity, which could be related to increased estrogen levels originating from its production by the adipose tissue. In addition, chronic inflammation and insulin resistance accompanying obesity have an impact of endometrial cancer [46]. To reduce its risk women should maintain a healthy weight.

\section{Prostate cancer}

Prostate cancer is the second most common type of cancer in American males. It affects men after age 55 and is more common in African-American males. Family history of prostate cancer and testosterone levels are contributing factors. Prostate cancer has been attributed to high consumption of animal fats, red meat, dairy products, and what was recently confirmed in a meta-analysis study, a high calcium intake $[23,47]$. Another meta-analysis of the observational studies showed a statistically significant association between soy consumption, rich in isoflavones (genistein and daidzein) and decreased risk of prostate cancer [48].

\section{Colon cancer}

Colon cancer is the third leading cause of death in American males, aged 55 and above. Diets high in saturated fat, red meat, alcohol, and obesity have been associated with an increased risk of colon cancer in both men and women. Also, inflammatory bowel disease (IBD), including either ulcerative colitis or Crohn's disease, as well as consumption of refined sugars and having sedentary life style are considered a risk of colorectal cancer. Some studies suggest that high fiber intake especially from whole grains and plant based diet, and high intake of calcium and vitamin $D$ alone or in combination can reduce the risk $[23,49]$.

\section{Lung cancer}

Lung cancer is the second leading cause of death in both men and women in the U.S. Its risk increases by about $50 \%$ in cigarette smokers, even secondhand smoke poses a significant risk. Other risk factors include occupational exposure to asbestos, radon, chromium, 
nickel and diesel exhaust. The effects of vitamins in lung cancers were not consistent. Observational study (VITAL) including 77,118 participants, 50 to 76 years of age showed that intake of vitamins $B_{6}$, folate, and $B_{12}$ did not affect lung cancer risk among women, however vitamin $B_{6}$ and $B_{12}$ from individual supplement sources, but not from multivitamins, was associated with higher lung cancer risk in men, in particular in smokers [50]. A controversy has been surrounding the effects of a high intake of beta carotene and vitamin A in lung cancer. A meta-analysis of randomized controlled trials with betacarotene supplementation concluded no effects of on lung cancer, with a slightly increased risk in smokers [51]. A case-cohort study in smokers and workers exposed to asbestos suggests that vitamin A may assist vitamin $D$ in preventing lung cancer among smokers [52]. It appears that the cessation of smoking, protection from second hand smoke, and radon exposure in addition to high intake of fruits and vegetables is the best recommendation for prevention of lung cancer $[49,53]$.

\section{Oral and esophageal cancer}

Oral and Esophageal Cancer accounts for 2-3\% of all cancers diagnosed in the United States. Esophageal cancer is the seventh leading cause of death in Americans with a survival rate of about $16 \%$. The main esophageal cancer subtypes are squamous-cell carcinoma and adenocarcinoma. Over the last 30 years, the incidence of squamous-cell carcinoma has decreased in several areas of the world, but adenocarcinoma has risen by over fourfold in the US, Australia and several areas of Europe; its incidence has particularly increased in men. Alcohol and tobacco are the two major risk factors for developing squamous cell carcinomas and while tobacco and gastro esophageal reflux has been implied in adenocarcinoma cancers [49,53,54]. Additionally, obesity also contributes to esophageal cancer. To decrease cancer risk the diet must be optimized, primarily to reduce calorie intake, monounsaturated fat and red or processed meat. Consumption of fruits, vegetables, and cereals, which are the major source of vitamins and fiber, should be adequate in the daily diet. Consumption of fried or broiled foods because of formation of heterocyclic amines must be avoided because of increasing risks of oral cancer including the salivary gland tumors. It has been shown that optimal intake of micronutrients like vitamin C, E, antioxidants, zinc, beta-carotene, and folate are effective in prevention of oral cancer [55].

\section{Stomach cancer}

Stomach cancer is on the decline. Its primary cause has been identified as a chronic infection of Helicobacter pylori. Many studies suggest that excessive salt intake in the diet, high consumption of smoked and pickled foods and processed meat can be linked to stomach cancer. Increased consumption of fruits and vegetables and a low-salt diet decreases risk of stomach cancer $[5,26,42,49]$.

\section{Liver cancer (Hepatocellular carcinoma)}

Liver cancer is a very aggressive cancer that has been increasing at a rapid rate. It is the third most lethal cancer worldwide. Development of liver cancer has been related to consumption of foods contaminated with aflatoxins, excessive alcohol intake and infections with Hepatitis B and C viruses [5,26,49,53].

\section{Specific Components in Food Affecting the Development of Cancer}

Plant based diet contain many natural components with cancer-preventive properties. At the same time, modern methods of agriculture and animal husbandry apply hundreds of chemicals (pesticides, fertilizers, hormones and antibiotics) which contaminate and affect the quality and safety of food [16,56]. Although exposure to traces of individual chemicals may not pose a significant health risk [57] these agents are commonly used in various combinations and potencies and repeated exposure to them for long periods negatively affects health [58-62]. Growth hormones and antibiotics used in animal farming; Pesticides and herbicides in plant-based foods; and chemical compounds such as bisphenol A (BPA) or phthalates that enter food from packaging can increase cancer risk by acting as hormonelike substances in the body. They can also become carcinogens through their cumulative effects on cellular metabolism. In addition, many synthetic antioxidants commonly used in food processing to prevent microbial contaminations, enhance flavor or prolong shelf-life can affect cancer risk [24,63].

\section{Dietary factors decreasing cancer risk}

The following dietary components have been associated with decreased risk of cancer:

Antioxidants: Antioxidants, including vitamins $C, E$, and $A$ and the trace mineral selenium, have been shown to reduce the risk of several types of cancers $[27,63,64]$.

Vitamin A and beta-carotene: Beta-carotene found in fruits and vegetables is an excellent free radical trapping agent, which provides effective protection against cancers of the lung, stomach, colon, prostate and cervix $[65,66]$. Although two of three major studies on lung cancer in smokers have found beta-carotene supplements to be associated with their increased risk of cancer [51,67], other studies found beta carotene and other antioxidants beneficial against lung cancer even in smokers [68] or having a modest preventive effect $[69,70]$.

Vitamin C: Epidemiological studies show that the incidence of many cancers inversely correlates with diets high in vitamin $\mathrm{C}[71,72]$. According to National Cancer Institute, vitamin C can protect against cancers of esophagus, stomach, rectum, and pancreas. It may also protect from developing cancers of breast, cervix, and lung. Animal studies indicate that even in organisms 
internally producing vitamin $\mathrm{C}$, a high intake of vitamin $C$ delays the onset of spontaneous mammary tumors, prevents skin cancer and controls colon, kidney and bladder cancers [73-76]. A study using a mouse model mimicking human metabolism in respect to a lack of vitamin $C$ synthesis and the production of endogenous human lipoprotein (a) (GULO-/-; L $\mathrm{L}\left(\mathrm{a}^{+}\right)$demonstrated that fewer of well-encapsulated and less invasive tumors develop in the presence of dietary vitamin C [77]. In addition to its antioxidant functions, Vitamin $C$ is essential for the immune system $[78,79]$ as well as for neutralization of carcinogenic nitrosamines and fecal mutagens [80]. It is important in supporting liver detoxifying enzymes and blocking the toxic effects of carcinogens, such as polycyclic hydrocarbons, organochlorine pesticides and heavy metals [81-85].

Vitamin E: Various epidemiological and animal studies suggest the role for vitamin $E$ especially in lowering colon cancers [86]. Its preventive role in prostate cancer has been a subject of controversy however; some studies suggest cancer preventive effects of gamma and delta tocopherols, but not alpha tocopherols [87].

Folic acid: It has been shown that folic acid taken with other nutrients found in fruits and vegetables can reduce the risk of some cancers $[24,27,42]$.

Lycopene's: Lycopene's are phytonutrients related to the vitamin A and beta-carotene group which are especially abundant in vegetables and fruits. Various in vitro, in vivo and human studies have demonstrated its role in preventing prostate and other cancers $[24,27,42,81,88]$.

Selenium: Dietary intake of selenium has shown to lower the risk for lung, prostate and colon cancers [89]. Selenium affects different cancer mechanisms, including antioxidant protection, detoxification, as well as halting cancer cells invasion among others [90].

Calcium: Foods rich in calcium have been shown to reduce the risk of colorectal cancer and possibly breast cancer [91,92], however it may increase the risk of prostate cancer [93]. It is suggested that calcium can prevent damage to intestinal lining cells by forming insoluble compounds with fatty acids and bile acids. It may also decrease cell proliferation in the colon lining, promote their differentiation as well as indirectly improve cell signaling in the differentiation and apoptosis pathways [94,95].

$\mathrm{N}$-acetyl-cysteine (NAC): $\mathrm{N}$-acetyl-cysteine is a powerful antioxidant, essential in the production of glutathione. NAC can block the metastatic potential of several cancer cell lines through inhibition of enzymes that stimulate tumor vascularization. Its administration may reduce toxicity of chemotherapeutic agents [96-98].

Copper and manganese: These minerals are necessary for various cellular functions, including optimal stability of connective tissue and free radical defense. Copper is a component of SOD antioxidant enzymes. Low tissue copper levels are found in some types of malignancies, especially the highly metastatic type. Copper salicylates can decrease tumor growth, metastases and increase the survival of animals with certain types of neoplasms [99].

Phytochemicals: Phytochemicals such as flavonoids, indoles, polyphenols, terpenes and others are present in cruciferous vegetables, garlic, onions, soy, green tea, berries, rosemary and many other plants. They have the ability to slowdown and even stop the progression of the carcinogenic process by acting at various stages of cancer development, including stimulation of the immune system, reducing inflammation, triggering apoptosis, neutralizing many carcinogens, as well as affecting hormonal metabolism in the body [100-103].

Cruciferous vegetables: Isothiocyanates and glucosinylates, indole-3-carbinol, brassinin, ascorbigen and sulphoraphane present in cruciferous vegetables, such as cabbage, broccoli, cauliflower and Brussels sprouts, can reduce the risk of colorectal cancer and other types of cancers $[24,30,88,104,105]$.

Garlic and onions: Active components such as diallyl sulfide, diallyl disulfide and diallyl trisulfide, have shown to reduce the risk of cancer $[30,88,100,101,106]$.

Soy flavonoids: Soybeans contain quercetin, anthocyanidin, procyanidin and phytochemicals such as genistein and daidzein which have estrogenic properties of apparent benefit in combating breast cancer [107], prostate cancer [108] and other cancers [109].

Green tea: Tea has many polyphenols and other constituents with antioxidant and anti-cancer properties. The major anti-cancer component of green tea is epigallocatechin gallate (EGCG) [110], but also other catechins in green and black tea extracts are effective [111].

Resveratrol: Red wine and skin of red grapes contain various polyphenols, of which resveratrol has been shown to inhibit human breast, blood and lung cancers in many in vitro and in vivo studies [112]. It is able to inhibit all carcinogenesis stages (e.g., initiation, promotion and progression) and displays other bioactive effects, including anti-inflammatory, anticarcinogenic, phytoestrogen and neuroprotective. However, resveratrol poor solubility and bioavailability is still being a challenge [113].

Curcumin: This main ingredient of Curcuma longa gives curry its yellow color. Its antioxidant and anticancer effects were demonstrated in various types of cancers such as leukemia, lymphoma, stomach, gastrointestinal, sarcoma, breast, and head and neck cancers. Among others, curcumin can slow the tumor growth, decrease angiogenesis and induce apoptosis [114]. 
Chlorophyllin: Is a water soluble derivative of chlorophyll which has shown strong anti-cancer activity in various in vitro and in vivo studies [115].

Berries: Strawberries and raspberries contain a phenolic acid known as ellagic acid, effective in reducing the risk of breast and lung cancers $[116,117]$.

Carnosol: This and other compounds present in rosemary can help in preventing breast cancer [118].

\section{Other natural compounds}

Fiber: Consumption of insoluble fiber, such as oat bran, is known to reduce the risk of colorectal cancer $[23,49,88,119]$.

Amino acids: Lysine and proline: L-lysine and L-proline are the building blocks of collagen and elastin, the key components of extracellular matrix (ECM). Lysine is essential for life, but is not produced in the body. Lysine can inhibit collagen digesting enzymes (MMPs and plasmin) involved in cancer growth, metastasis and angiogenesis, and together with vitamin $C$ contribute to optimal stability of ECM as an important barrier hindering cancer cells invasion and metastasis [120].

\section{Food factors increasing cancer risk}

The following chemical compounds present in or added to food have been associated with increased risk of cancer (Figure 1).

Charcoal-broiled meat: Heterocyclic amines (HCAs) and polycyclic aromatic hydrocarbons (PAHs) generated during frying or charcoal-broiling of meat at very high temperatures are mutagenic and carcinogenic. Their consumption has been linked to stomach, colon and rectal cancers. Similarly, smoked meat contains aromatic hydrocarbons such as benzopyrenes, which are potential carcinogenic compounds $[49,53,121]$.

Red meat: The consumption of red meat increases the risk of colorectal cancer [24].

Nitrites: Nitrites present in meat and meat products to maintain color and retard bacterial contamination are converted to nitrosamines by intestinal bacteria, which can increase the risk of stomach cancer. Fruits and vegetables rich in vitamin $C$ can inhibit the conversion of nitrites to nitrosamines [58].

Salt: Most of the salt consumed in the diet is derived from processed food increasing the risk of stomach and throat cancers $[49,53]$.

Saturated fat and trans-fatty acids: A diet rich in fat (saturated fats) is associated with an increased risk of cancer of the lung, colon, rectum, breast, endometrium, and prostate. Trans-fatty acids are produced during the hydrogenation process of oil and margarine [122].

Alcohol: Although, moderate alcohol consumption, especially red wine, may have beneficial effects, there is convincing evidence linking excessive alcohol intake with an increased risk of liver, breast, colon, rectum, oral and esophageal cancers $[23,25]$.

Sweeteners: Saccharin, cyclamate, and aspartame: Cyclamate is not carcinogenic itself, but when combined with saccharin it produced bladder tumors in rats, which led to its ban in the US. Later studies showed that saccharin in high doses promoted tumors of the bladder and other sites in experimental animals. Saccharin was banned in Canada, but the controversy surrounding the consumption of this and other artificial sweeteners still exists [123]. Aspartame sold under the brand name NutraSweet or Equal has been associated with developing lymphoma and leukemia in rats, and brain tumors. However, epidemiology studies did not find that its consumption increases the risk of cancer [124]. Acesulfame-K, a relatively new artificial sweetener found in baking goods, gum and gelatin, has not been thoroughly tested, however it has been linked to kidney tumors [125].

\section{Food Additives, Pesticides and Herbicides and Cancer}

Wide application of artificial food additives, herbicides and pesticides has triggered decades long controversial debate regarding their negative health effects, including development of cancer. Their ubiquitous use is a billion dollar business, which does not refrain from
$\mathrm{NaNO}_{2}$

Sodium nitrite
$\mathrm{NaNO}_{3}$

Sodium nitrate

\section{$\mathrm{C}_{2} \mathrm{H}_{5} \mathrm{OH}$}

Ethyl alcohol<smiles>[N+]N1C(=O)c2ccccc2S1(=O)=O</smiles>

Sodium saccharin<smiles>O=S(=O)(NC1CCCCC1)O[Na]</smiles>

Sodium cyclamate

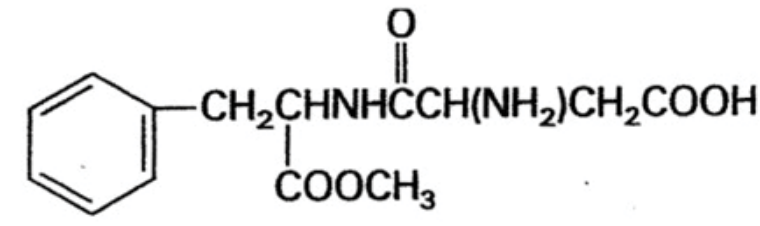

Aspartame

Figure 1: Chemical compounds found in food and which are implied in increased risk of cancer. 
using its economic power to influence regulators, politicians, media and scientists in taking a stance in favor of their products. The links of food additives and pesticides to an increase in cancer and other health problems have been surrounded by conflicts of interest arguments about the use of industry sponsored studies to pressure the regulators and deceive the public [126]. Most of the discussed health concerns have been related to the use of individual components in food however, every person, including children and the elderly is exposed to numerous artificial agents and their cumulative effects on human health have not been studied and are not considered in establishing regulatory guidelines.

\section{Food additives}

Butylated hydroxyanisole (BHA), butylated hydroxytoluene (BHT), propyl gallate: Butylated hydroxyanisole (BHA), butylated hydroxytoluene (BHT), propyl gallate and others, are routinely added during food processing as preservatives and are found in cereals, chewing gum, potato chips, and vegetable oils. It has been shown that they can affect the neurological system of the brain and have a potential to cause cancer. BHA and $\mathrm{BHT}$ are oxidants that form cancer-causing reactive compounds in our body [127].

Potassium bromate: Potassium bromate is used to increase volume in some white flour bread products and it is known to cause cancer in animals. Even its small amounts in bread can create problems for humans [128].

Fluoride: Fluoride is added to water and many dental products to prevent tooth cavities and enhance bone mineralization. As of 2008 more than $72 \%$ of the US population served by public water system has access to fluoridated water. Some animal studies have linked fluoride to the development of bladder cancer, osteosarcoma and thyroid cancers, however, the evidence is not strong enough to confirm a direct link between human cancers and fluoridation [129].

Food dyes: Many commonly used colorants have been associated with dangerous side effects [130].

Blue \#1 and blue \#2 (E133): These dyes found in candy, cereal, soft drinks, sports drinks and pet foods are banned in Norway, Finland, and France as causing chromosomal damage.

Red dye \#3 (also Red \#40-a more current dye) (E124): After eight years of debate these dyes were banned from use in many foods and cosmetics in 1990; however, they are on the market until supplies run out. Red dye has been associated with thyroid cancer and chromosomal damage in laboratory animals. It is found in fruit cocktail, maraschino cherries, ice cream, candy, bakery products and more.

Yellow \#6 (E110) and yellow tartrazine (E102): They are banned in Norway and Sweden. The dye increases the number of kidney and adrenal tumors in laboratory animals and it may cause chromosomal damage. It is found in American cheese, macaroni and cheese, candy and carbonated beverages, lemonade and other.

Other additives and chemical compounds find their way into the food supply through agricultural use, animal farming, or food processing, even if their use is not directly intended for human consumption.

\section{Pesticides and herbicides}

Their exposure levels are regulated by the EPA in the US and by other environmental agencies internationally. However, safety levels of these powerful toxins are being determined based on the dose when they are applied as individual compounds. Many animal studies found numerous pesticides as carcinogenic, (e.g., organochlorines, creosote, and sulfallate) and tumor promoters (the organochlorines DDT, chlordane, and lindane) $[59,60]$. In humans, arsenic compounds and insecticides used occupationally have been classified as carcinogens by the International Agency for Research on cancer $[131,132]$. Human data, however, are limited by the small number of studies that evaluate individual pesticides, a lack of data for exposure to multiple pesticides, and by conflict of interests in industry-sponsored research. Epidemiologic studies, although sometimes contradictory, have linked phenoxy acid herbicides or contaminants in them with soft tissue sarcoma (STS) and malignant lymphoma [132]; Organochlorine insecticides are linked with STS, non-Hodgkin's lymphoma (NHL), leukemia, and, less consistently, with cancers of the lung and breast [127] and triazine herbicides with ovarian cancer [128,131,132]; Organophosphorus compounds are linked with NHL and leukemia [133-135]. An excessive incidence of non-Hodgkin's lymphoma (NHL) has been reported among farmers and other occupational groups working with pesticides. Some pesticides exhibit immunotoxin and genotoxic activities. Individuals exposed to pesticides have also been found to have an increased prevalence of chromosomal abnormalities including the $t(14 ; 18)(q 32 ; q 21)$, one of the most common chromosomal abnormalities in NHL [135]. The epidemiologic studies reported that the association between pesticide exposures and risk of NHL was largely limited to NHL cases with the chromosomal translocation $\mathrm{t}(14 ; 18)$ [135].

\section{Glyphosate}

Glyphosate, under a commercial name "Round-up" is the world's most widely used weed killer applied in agriculture, forestry, and domestic gardening. Monsanto and other companies have developed genetically engineered seeds that can tolerate glyphosate, allowing farmers to apply it to entire fields without destroying crops, but contaminating water, soil and endangering insects and other animal species [61,62]. The International Agency for Research on Cancer (IARC) 
concluded in 2015 that glyphosate is a "probable human carcinogen", based on "limited evidence" of carcinogenicity in humans and "sufficient evidence" in experimental animals. In three out of the four human studies of American, Canadian, and Swedish agricultural workers, the IARC panel found a link between glyphosate and non-Hodgkin lymphoma, a cancer of the immune system. Evidence from animal studies also showed a link between glyphosate and rare kidney and pancreatic cancers and other cancers [136]. Cell-based studies showed abnormal changes to cell DNA and cell death when exposed to even low concentrations of glyphosate [137]. The Glyphosate-cancer-link controversy is an example of industry pressure on scientists and heavy lobbying in protecting the multi-billion-dollar agent like glyphosate. In this, Monsanto and other companies do not refrain from discrediting independent research and international scientific findings, which includes launching personal attacks in the media on scientists with an established track record and scientific credibility if they present contradictory views.

\section{Possible Mechanism(s) Involved in Cancer Inhibition by Dietary Components}

Chemical carcinogenesis is a multistage process occurring over a relatively long period of time. It is a very complex process involving various interactions between genes, the environment, and cellular metabolism [138]. In general, there are two types of carcinogens: Those that damage DNA directly (genotoxic carcinogens) and those that use mediators in causing DNA damage (non-genotoxic carcinogens). Most of them like other xenobiotics in the body undergo extensive transformation in the liver, carried out by Phase I and Phase II drug metabolizing enzymes. Phase I components are related to the metabolism of chemicals and include cytochrome P-450 and mixed function oxygenase activity. Phase II components are involved in conjugation and detoxification process. Phytochemicals and others natural compounds mostly boost the induction of Phase II enzymes $[139,140]$ and inactivate Phase I enzymes. Chemical substances that affect these two enzyme systems could also modify cancer risk. They can be divided into three categories.

\section{Precursor conversion inhibitors}

This category includes agents that prevent the formation of active carcinogens and includes ascorbic acid, alpha tocopherol and others.

\section{Blocking agents}

This group of anti-carcinogens prevents carcinogens from damaging cellular macromolecules such as DNA. It includes quercetin, genistein, indole 3-carbinol, but also some chemicals used in food preservation: BHA, BHT.

\section{Suppressing agents}

These agents act primarily by inhibiting tumor promotion and include selenium salts, retinoids, carotenoids, BHA, benzyl isothiocyanate and others.

\section{New Direction in the Application of Micronu- trients against Cancer: Synergy Approach}

A modern scientific research increasingly strives to explore and harness the anti-cancer potential of natural compounds. It is represented by a research direction that aims at increasing efficacy of micronutrients through their synergistic interactions. It has been shown that such synergistically acting combinations of nutrients display pleiotropic effects against cancer by simultaneously affecting different mechanisms involved in malignancy Initial results indicating enhanced anticancer efficacy of nutrient synergy approach were published in 2003 [141]. To date, over 100 studies using in vitro and in vivo approaches have confirmed the multiple anti-cancer mechanisms affected by the two specific nutrient synergies (Table 1) (www. drrathresearch.org).

Studies conducted in over 50 human cancer cell types including skin, liver, breast, prostate, colon, kidney, leukemia and fibrosarcoma have shown that a synergistic combinations of several nutrients can inhibit the multiplication of cancer cells and tumor growth, stop cancer cell invasion, and curb angiogenesis and metastasis [142]. In addition, nutrient synergy was effective in triggering the apoptotic process in various types of cancer cells [143-145]. The synergistic combination of vitamin C, select amino acids, polyphenols, and other compounds was also effective in controlling the inflammation process, triggering anti-cancer changes in gene expression, and other metabolic aspects accompanying cancer initiation and progression (Table 2) $[146,147]$. Their anti-cancer efficacy was superior to the effects achieved with individual components in these mixtures $[103,148]$. Especially encouraging are the anti-metastatic effects of this nutrient synergy approach, since today there are no effective therapeutic means to stop cancer

Table 1: Nutrients contained in two tested natural anti-cancer synergy compositions.

Multi-nutrient Synergy 1

\begin{tabular}{|c|c|c|c|c|}
\hline \multicolumn{4}{|c|}{ Multi-nutrient Synergy 1} & \multirow{2}{*}{ Phyto-Synergy 2} \\
\hline Vitamins & Amino acids & Minerals & Polyphenols & \\
\hline \multirow[t]{5}{*}{ Vitamin C } & L-Lysine & Selenium & Green tea (EGCG) & Curcumin \\
\hline & L-Proline & Copper & Quercetin & Cruciferex $^{\circledR}$ \\
\hline & L-Arginine & Manganese & & Green tea extract (EGCG) \\
\hline & $\mathrm{N}$-acetyl Cysteine & & & Quercetin \\
\hline & & & & Resveratrol \\
\hline
\end{tabular}


Table 2: Anti-cancer effects of individual food components and natural compounds combined in Nutrient Synergy.

\begin{tabular}{|c|c|}
\hline Process in Cancer & Beneficial effects/mechanisms \\
\hline \multirow{5}{*}{ Oxidative stress } & Scavenging free radicals \\
\hline & Reduced oxidative stress* \\
\hline & Prevent DNA damage \\
\hline & Inhibition of nitration and nitrosation \\
\hline & Inhibition of Xanthine oxidase \\
\hline \multirow{4}{*}{ Cancer cell growth and survival } & Inhibition of cell proliferation* \\
\hline & Inhibition of cell differentiation \\
\hline & Cell-cycle arrest ${ }^{*}$ \\
\hline & Induction of apoptosis ${ }^{*}$ \\
\hline \multirow{5}{*}{ Tumor growth and metastasis } & Inhibition of angiogenesis* \\
\hline & Inhibition of cancer cells adhesion and invasion ${ }^{*}$ \\
\hline & Inhibition of proteolytic destruction of connective tissue (MMPs, uPA)* \\
\hline & Increased synthesis of proteolysis inhibitors TIMP 1 and $2, \mathrm{PAI}{ }^{*}$ \\
\hline & Tumor encapsulation* \\
\hline \multirow{3}{*}{ Genetic } & Inhibition of oncogene expression ${ }^{*}$ \\
\hline & Induction of tumor suppressor genes* \\
\hline & DNA repair \\
\hline \multirow{3}{*}{ Initiation/prevention } & Support of detoxification process: \\
\hline & Induction of Phase II enzymes, Glutathione peroxidase, Catalase, SOD \\
\hline & Inhibition Phase I enzymes (blocking activation of carcinogens) \\
\hline \multirow{2}{*}{ Support systems } & Immune system enhancement \\
\hline & Anti-inflammatory effects (inhibition of COX2, inducible iNOS) ${ }^{*}$ \\
\hline \multirow{3}{*}{ Metabolic effects } & Steroid hormone metabolism regulation \\
\hline & Modulation of glutamate metabolism \\
\hline & Modulation of glycolytic and epithelial mesenchymal transition (EMT) genes expression* \\
\hline
\end{tabular}

*Experimentally confirmed anti-cancer effects of Nutrient Synergy.

metastasis. The natural synergy approach targets a common mechanism essential in cancer invasion and metastasis, which is enzymatic destruction of connective tissue surrounding cancer cells, and at the same time supporting optimal synthesis of this tissue. These antimetastatic effects of a specific combination of nutrients have been confirmed in melanoma and other cancers [142,148].

Taking into account general safety and also the economic advantage of natural compounds, this new direction in cancer research opens up a chance for developing effective control of cancer without the detrimental side effects and skyrocketing costs of current conventional approaches.

\section{Conclusions}

The new nutrient synergy approach exemplifies the need for a new direction in taking advantage of multiple health benefits of food components in human health. Current research also indicates urgent needs in comprehensive evaluation of the health impacts of chemical additives used in food production and processing especially their cumulative effects resulting from multiple interactions involving synergy, antagonism, or additive effects. Natural diet-based approaches have a great advantage as being non-toxic, well tolerated, and with very few, if any, side effects. They have been increasingly accepted and already applied as adjuncts to alleviate toxic effects associated current conventional chemo- and radiation-therapies and their therapeutic potential should be evaluated in human studies.

\section{References}

1. (2018) Cancer Statistics. National Cancer Institute.

2. Siegel RL, Miller KD, Jemal A (2018) Cancer Statistics. CA Cancer J Clin 68: 7-30.

3. Ma X, Yu H (2006) Global Burden of Cancer. Yale J Biol Med 79: 85-94.

4. Jemal A, Ward EM, Johnson CJ, Cronin KA, Ma J, et al. (2017) Annual report to the Nation on the status of cancer, 1975-2014, Featuring Survival. J Natl Cancer Inst 109: $1-22$.

5. Fitzmaurice C, Allen C, Barber RM, Barregard L, Bhutta ZA, et al. (2017) Global, Regional, and National cancer incidence, mortality, years of life lost, years lived with disability, and disability-adjusted life-years for 32 cancer groups, 1990 to 2015. A Systematic Analysis for the Global Burden of Disease Study. JAMA Oncol 3: 524-548.

6. WHO (2018) International Agency for Research on Cancer.

7. (2007) Food, nutrition, physical activity, and the prevention of cancer: A Global perspective. American Institute for Cancer Research, Washington DC, U.S.A.

8. Hutchison GB (1976) Epidemiology of prostatic cancer. Semin Oncol 3: 151-159.

9. Shimizu H, Ross RK, Bernstein L, Yatani R, Henderson BE, et al. (1991) Cancers of the prostate and breast among Japanese and White Immigrants in Los Angeles County. $\mathrm{Br}$ J Cancer 63: 963-966.

10. Ziegler RG, Hoover RN, Pike MC, Hildesheim A, Nomura AM, et al. (1993) Migration patterns and breast cancer risk 
in Asian-American Women. J Natl Cancer Inst 85: 18191827.

11. Haenszel W, Kurihara M (1968) Studies of Japanese migrants. I. Mortality from cancer and other diseases among Japanese in the United States. J Natl Cancer Inst 40: 43-68.

12. Parkin DM (2006) The Global health burden of infectionsssociated cancers in the year 2002. Int J Cancer 118: 3030-3044.

13. Ko Hiu T, Goodman MT, Wu AH, McDuffie K, Wilkens LR, et al. (2004) Aggregation of ovarian cancer with breast, ovarian, colorectal and prostate cancer in first-degree relatives. Am J Epidemiol 159: 750-758.

14. Furati F, Negri E, La Veccia C (2014) Family history and the risk of cancer: Genetic factors influencing multiple cancer sites. Expert Review of Anticancer Therapy 14: 1-4.

15. Irigaray P, Newby JA, Clapp R, Hardell L, Howard V, et al. (2007) Lifestyle-related factors and Environmental agents causing cancer: An overview. Biomed Pharmacother 61: 640-658.

16. Carr $\mathrm{BI}$ (1985) Chemical carcinogens and inhibitors of carcinogenesis in the human diet. Cancer 55: 218-224.

17. Steenland K, Burnett C, Lalich N, Ward E, Hurrell J (2003) Dying for work: The magnitude of US mortality from selected causes of death associated with occupation. Am J Ind Med 43: $461-482$

18. Yan $\mathrm{H}$ (2018) Jurors give $\$ 289$ million to a man they say got cancer from Monsanto's Roundup weedkiller.

19. Aleman BM, Van den Belt Dusebout AW, Klokman WJ, Van't Veer MB, Bartelink H, et al. (2003) Long-term causespecific mortality of patients treated for Hodgkin's disease. J Clin Oncol 21: 3431-3439.

20. Wolff AC, Blackford AL, Visvanathan K, Rugo HS, Moy B, et al. (2015) Risk of marrow neoplasms after adjuvant breast cancer therapy: The National comprehensive cancer network experience. J Clin Oncol 33: 340-348.

21. Dy GK, Adjei AA (2013) Understanding, recognizing, and managing toxicities of targeted anticancer therapies. CA Cancer J Clin 63: 249-279.

22. Patel CJ, Ji J, Sundquist J, loannidis JP, Sundquist K (2016) Systematic assessment of pharmaceutical prescriptions in association with cancer risk: A method to conduct a population-wide medication-wide longitudinal study. Sci Rep 6: 31308

23. Miller AB (1990) Diet and Cancer. Reviews in Oncology 13 : 325-341.

24. Michel KB (2005) The Role of nutrition in cancer development and prevention. Int J Cancer 114: 163-165.

25. Anand $P$, Kunnumakara $A B$, Sundaram $C$, Harikumar $K B$ Tharakan ST, et al. (2008) Cancer is a preventable disease that requires major lifestyle changes. Pharm Res 25: 20972116.

26. (1996) Guidelines on diet, nutrition and cancer prevention: Reducing the risk of cancer with healthy food choices and physical activity. The American Cancer Society 1996 Advisory Committee on Diet, Nutrition and Cancer Prevention. CA Cancer J Clin 46: 325-341.

27. Donaldson MS (2004) Nutrition and Cancer: A Review of the evidence for Anti-cancer diet. Nutr J 3: 1-21.

28. Campbell TC (2017) Cancer prevention and treatment by wholistic nutrition. J Nat Sci 3: e448.
29. Webster RP, Gawde MD, Bhattacharya RK (1996) Modulation of carcinogen-induced DNA damage and repair enzyme activity by dietary riboflavin. Cancer Lett 98: 129135.

30. Lui RH (2004) Potential synergy of phytochemicals in cancer prevention: Mechanism of action. J Nutr 134: 3479S-3485S.

31.(1994) The alpha-tocopherol, beta-carotene lung cancer prevention study: Design, methods, participant characteristics, and compliance. The ATBC Cancer Prevention Study Group. Ann Epidemiol 4: 1-10.

32. Omenn GS, Goodman GE, Thornquist MD, Balmes J, Cullen MR, et al. (1996) Risk factors for lung cancer and for intervention effects in CARET, the beta-carotene and retinol efficacy trial. J Natl Cancer Inst 88: 1550-1559.

33. Kaczmarczyk MM, Miller MJ, Freund GG (2012) the health benefits of dietary fiber: Beyond the usual suspects of Type 2 diabetes mellitus, cardiovascular disease and colon cancer. Metabolism 61: 1058-1066.

34. Nomura AM, Hankin JH, Henderson BE, Wilkens LR, Murphy SP, et al. (2007) Dietary fiber and colorectal cancer risk: The multiethnic cohort study. Cancer Causes Control 18: $753-764$

35. Gröber U, Holzhauer P, Kisters K, Holick MF, Adamietz IA (2016) Micronutrients in oncological intervention. Nutrients 8: $163-193$

36. Ströhle A, Zänker K, Hahn A (2010) Nutrition in oncology: The case of micronutrients (review). Oncol Rep 24: 815828.

37. Van Bokhorst-de van der Schueren MA (2005) Nutritional support strategies for malnourished cancer patients. Eur J Oncol Nurs 9: S74-S83.

38. Prasad KN, Cole WC (2006) Antioxidants in cancer therapy. J Clin Oncol 24: e8-e9.

39. Prasad KN (2004) Rationale for using high-dose multiple dietary antioxidants as an adjunct to radiation therapy and chemotherapy. J Nutr 134: 3182S-3183S.

40. Prasad KN, Cole WC, Kumar B, Prasad KC (2001) Scientific rationale for using high-dose multiple micronutrients as an adjunct to standard and experimental cancer therapies. $J$ Am Coll Nutr 20: 450S-475S.

41. Gallus S, Bosetti C, La Vecchia C (2004) Mediterranean diet and cancer risk. Eur J Cancer Prev 13: 447-452.

42. Key TJ (2011) Fruit and vegetables and cancer risk. Br J Cancer 104: 6-11.

43. Anand $P$, Sundaram $C$, Jhurani $S$, Kunnumakkara $A B$, Aggarwal BB (2008) Curcumin and cancer: An "Old-age" disease with an "Age-old" solution. Cancer Lett 267: 133164.

44. Dong JY, Qin LQ (2011) Soy isoflavones consumption and risk of breast cancer incidence or recurrence: A metaanalysis of prospective studies. Breast Cancer Res Treat 125: $315-323$

45. Willett W (2003) Lessons from dietary studies in Adventists and questions for the future. Am J Clin Nutr 78: 539S-543S.

46. Onstad MA, Schmandt RE, Lu KH (2016) Addressing the role of obesity in endometrial cancer risk, prevention, and treatment. J Clin Oncol 34: 4225-4230.

47. Rahmati S, Azami M, Delphisen A, Ahmadi MRH, Sayehmiri $\mathrm{K}$ (2018) Total calcium (Dietary and supplementary) intake and prostate cancer: A systematic review and meta- 
analysis, Asian Pac J Cancer Prev 19: 1449-1456.

48. Applegate CC, Rowles JL, Ranard KM, Jeon S, Erdman JW (2018) Soy consumption and the risk of prostate cancer: An updated systematic review and meta-analysis. Nutrients 10: E40.

49. Key TJ, Allen NE, Spencer EA, Travis RC (2002) The effect of diet on risk of cancer. Lancet 360: 861-868.

50. Breasky TM, White E, Chen CL (2017) Long-Term, supplemental, one-carbon metabolism-related vitamin $B$ use in relation to lung cancer risk in the vitamins and lifestyle (VITAL) Cohort. J Clin Oncol 35: 3440-3448.

51. Jeon YJ, Myung SK, Lee EH, Kim Y, Chang YJ, et al. (2011) Effects of beta-carotene supplements on cancer prevention: Meta-analysis of randomized controlled trials. Nutr Cancer 63: 1196-1207.

52. Cheng TY, Goodman GE, Thornquist MD, Barnett MJ, Beresfort SA, et al. (2014) Estimated intake of vitamin D and its interaction with vitamin $A$ on lung cancer risk among smokers. Int J Cancer 135: 2135-2145.

53. Key TJ, Schatzkin A, Willett WC, Allen NE, Spencer EA, et al. (2004) Diet, nutrition and prevention of cancer. Public Health Nutrition 7: 187-200.

54. Levi F, Randimbison L, Lucchini F, Te VC, La Vecchia C (2001) Epidemiology of adenocarcinoma and squamous cell carcinoma of the oesophagus. Eur J Cancer Prev 10: 91-96.

55. Jessri M, Rashidkhani B, Hajizadeh B, Jessri M, Gotay C (2011) Macronutrients, vitamins and minerals intake and risk of esophageal squamous cell carcinoma: A casecontrol study in Iran. Nutr J 10: 137.

56. Doll R, Peto R (1981) The Cause of Cancer. Quantitative estimates of avoidable risk of cancer in the United States today. J Natl Cancer Inst 66: 1191-1308.

57. Ames BN (1983) Dietary carcinogens and anticarcinogens. Science 221: 1256-1264.

58. De Kok TM, Van Breda SG, Manson MM (2008) Mechanism and combined action of different chemopreventive dietary compounds. Eur J Nutr 47: 51-59.

59. Dich J, Zahm SH, Hanberg A, Adami HO (1997) Pesticides and cancer. Cancer Causes Control 8: 420-443.

60. Purdue MP, Hoppin JA, Blair A, Dosemeci M, Alavanja MC (2007) Occupational exposure to organochlorine insecticides and cancer incidence in the agricultural health study. Int J Cancer 120: 642-649.

61. Mink PJ, Mandel JS, Sceurman BK, Lundin JI (2012) Epidemiologic studies of glyphosate and cancer: A Review. Regul Toxicol Pharmacol 63: 440-452.

62. De Roos AJ, Blair A, Rusiecki JA, Hoppin JA, Svec M, et al. (2005) Cancer incidence among glyphosate exposure, pesticide applicator in agriculture health study. Environ Health Perspect 113: 49-54.

63. https://www.cancer.org/healthy/eat-healthy-get-active/acsguidelines-nutrition-physical-activity-cancer-prevention/ food-additives.html

64. Weisburger JH (1991) Nutritional approach to cancer prevention with emphasis on vitamins, antioxidants and carotinoids. Am J Clin Nutr 53: 226S-237S.

65. Vance TM, Su J, Fontham ET, Koo SI, Chun OK (2013) Dietary antioxidants and prostate cancer: A Review. Nutr Cancer 65: 793-801.
66. (1998) IARC Handbook of cancer prevention: Carotenoids. Volume 2, International Agency for Research on Cancer, WHO. Oxford University Press, Oxford, UK.

67. Albanes D, Heinonen OP, Taylor PR, Virtamo J, Edwards BK, et al. (1996) Alpha-tocopherol and Beta-carotene supplements and lung cancer incidence in the alphatocopherol, beta-carotene cancer prevention study: Effects of base-line characteristics and study compliance. J Natl Cancer Inst 88: 1560-1570.

68. Shareck M, Rousseau MC, Koushik A, Siemiatycki J, Parent ME (2017) Inverse association between dietary intake of selected carotenoids and vitamin $c$ and risk of lung cancer. Front Oncol 7: 23-35.

69. Männistö S, Smith Warner SA, Spiegelman D, Albanes D, Anderson K, et al. (2004) Dietary carotenoids and risk of lung cancer in a pooled analysis of seven cohort studies. Cancer Epidemiol Biomarkers Prev 13: 40-48.

70. Holick CN, Michaud DS, Stolzenberg Solomon R, Mayne ST, Pietinen P, et al. (2002) Dietary carotenoids, serum beta-carotene, and retinol and risk of lung cancer in the alpha-tocopherol, beta-carotene cohort study. Am J Epidemiol 156: 536-547.

71. Block G (1991) Vitamin C and cancer prevention: The epidemiologic evidence. Am J Clin Nutr 53: 270S-282S.

72. Enstrom JE, Kanim LE, Klein MA (1992) Vitamin C intake and mortality among a sample of the United States population. Epidemiology 3: 194-202.

73. Tsao CS (1991) Inhibiting effect of ascorbic acid on the growth of human mammary tumor xenografts. Am J Clin Nutr 54: 1274S-1280S.

74. Pauling $L$ (1991) Effect of ascorbic acid on incidence of spontaneous mammary tumors and UV-light-induced skin tumors in mice. Am J Clin Nutr 54: 1252S-1255S.

75. Polireddy K, Dong R, Reed G, Yu J, Chen P, et al. (2017) High dose parenteral ascorbate inhibited pancreatic cancer growth and metastasis: Mechanisms and a Phase I/Ila study. Sci Rep 7: 17188.

76. Chen Q, Espey MG, Sun AY, Pooput C, Kirk KL, et al. (2008) Pharmacologic doses of ascorbate act as a prooxidant and decrease growth of aggressive tumor xenografts in mice. Proc Natl Acad Sci U S A 105: 11105-11109.

77. Cha J, Roomi MW, Ivanov V, Kalinovsky T, Niedzwiecki A, et al. (2013) Ascorbate supplementation inhibits growth and metastasis of b16fo melanoma and $4 \mathrm{t} 1$ breast cancer cells in vitamin C-deficient mice. Int J Oncol 42: 55-64.

78. Carr AC, Maggini S (2017) Vitamin C and immune function. Nutrients 9: E1211-E1236.

79. Sorice A, Guerriero E, Capone F, Colonna G, Castello G, et al. (2014) Ascorbic acid: Its role in immune system and chronic inflammation diseases. Mini Rev Med Chem 14: 444-452.

80. Tannenbaum SR (1989) Preventive action of vitamin c on nitrosamine formation. Int J Vitam Nutr Res Suppl 30: 109113.

81. Weisburger JH (1991) Carcinogenesis in our food and cancer prevention. Asv Exp Med Biol 289: 271-280.

82. Fong YY, Chan WC (1976) Effect of ascorbate on aminenitrite carcinogenicity. IARC Sci Publ 14: 461-464.

83. Oliveira CP, Kassab P, Lopasso FP, Souza HP, Janiszewski M, et al. (2003) Protective effect of ascorbic acid in experimental gastric cancer: reduction of oxidative 
stress. World J Gastroenterol 9: 446-448.

84. Roomi MW, Netke S, Tsao C (1998) Modulation of drug metabolizing enzymes in guinea pig liver by High intakes of ascorbic acid. Int J Vitam Nutr Res 68: 42-47.

85. Roomi MW, Tsao CS (1996) Ascorbic acid protection of guinea pigs against $\beta$-aminopropionitrile induced Neurolathyrism. Research Communications in Biological Psychology and Psychiatry 20: 113-122.

86. Bostick RM, Potter JD, McKenzie DR, Sellers TA, Kushi $\mathrm{LH}$, et al. (1993) Reduced risk of colon cancer with high intake of vitamin E: The iowa health study. Cancer Res 53: 4230-4237.

87. Yang CS, Suh N, Kong AN (2012) Does vitamin E prevent or promote cancer? Cancer Prev Res (Phila) 5: 701-705.

88. Valinio $H$, Weiderpass $E$ (2006) Fruits and vegetables in cancer prevention. Nutr Cancer 54: 111-142.

89. Cai X, Wang C, Yu W, Fan W, Wang S, et al. (2016) Selenium exposure and cancer risk: An updated Metaanalysis and Meta-regression. Sci Rep 6: 1-8.

90. Yoon SO, Kim MM, Chung AS (2001) Inhibitory effect of selenite on invasion of ht1080 tumor cells. J Biol Chem 276: 20085-20092.

91. Abbas S, Linseisen J, Rohrmann S, Chang Claude J, Peeters PH, et al. (2013) Dietary intake of vitamin D and calcium and breast cancer risk in the European Prospective Investigation into Cancer and Nutrition. Nutr Cancer 65: 178-187.

92. McCullough ML, Rodriguez C, Diver WR, Feigelson HS, Stevens VL, et al. (2005) Dairy, calcium and vitamin D intake in postmenopausal breast cancer risk in the Cancer Prevention Study II Nutrition Cohort. Cancer Epidemiol Biomarkers Prev 14: 2898-2904.

93. Ahn J, Albanes D, Peters U, Schatzkin A, Lim U, et al. (2007) Dairy products, calcium intake, and risk of prostate cancer in the prostate, lung, colorectal, and ovarian cancer screening trial. Cancer Epidemiol Biomarkers Prev 16: 2623-2630.

94. Millner JA, McDonalds SS, Anderson DE, Greenwald P (2001) Molecular targets for nutrients involved with cancer prevention. Nutr Cancer 41: 1-16.

95. Lamprecht SA, Lipkin M (2001) Cellular mechanisms of calcium and vitamin $D$ in the inhibition of colorectal carcinogenesis. Ann N Y Acad Sci 952: 73-87.

96. Meister A (1994) Glutathione-ascorbic acid antioxidant system in animals. J Biol Chem 269: 9397-9400.

97. Kawakami S, Kageyama Y, Fujii Y, Kihara K, Oshima H (2001) Inhibitory effect of $\mathrm{N}$-acetylcysteine on invasion and MMP-9 production of T24 human bladder cancer cells. Anticancer Res 21: 213-219.

98. Kelly RG, Nally K, Shanahan F, O'Connell J (2002) Type insulin-like growth factor receptor expression on colorectal adenocarcinoma cell lines is decreased in response to the chemopreventive agent N-acetyl-I-cysteine. Ann N Y Acad Sci 973: 555-558.

99. Fan L, Tian M, Liu Y, Deng Y, Liao Z, et al. (2017) Salicylate phenanthroline copper (II) Complex induces apoptosis in triple-negative breast cancer cells. Oncotarget 8: 2982329832.

100. ARM Ruhul Amin, Omer Kucuk, Fadlo R Khuri, Dong M Shin (2009) Perspective for cancer prevention with natural compounds. J Clin Oncol 27: 2712-2725.
101. Thomas R, Butler E, Macchi F, Williams M (2015) Phytochemicals in cancer prevention and management. Brit J Med Pract 8: a815.

102. Wattenberg LW (1983) Inhibition of neoplasia by minor dietary constituents. Cancer Res 43: 2448s-2453s.

103. Niedzwiecki A, Roomi MW, Kalinovsky T, Rath M (2016) Anticancer efficacy of polyphenols and their combinations. Nutrients 8: 552

104. Izutani Y, Yogosawa S, Sowa Y, Sakai T (2012) Brassinin induces $\mathrm{G} 1$ phase arrest through increase of p21 and p27 by inhibition of the phosphatidylinositol 3-kinase signaling pathway in human colon cancer cells. Int J Oncol 40: 816824.

105. Martin SL, Kala R, Tollefsbol TO (2018) Mechanisms for the inhibition of colon cancer cells by sulforaphane through epigenetic modulation of MicroRNA-21 and human telomerase reverse transcriptase (hTERT) downregulation. Curr Cancer Drug Targets 18: 97-106.

106. Puccinelli MT, Stan SD (2017) Dietary bioactive diallyl trisulfide in cancer prevention and treatment. Int J Mol Sci 18: 1645 .

107. Xie Q, Chen ML, Qin Y, Zhang QY, Xu HX (2013) Isoflavone consumption and risk of breast cancer: A doseresponse meta-analysis of observational studies. Asia Pac J Clin Nutr 22: 118-127.

108. Sak K (2017) Current epidemiological knowledge about the role of flavonoids in prostate carcinogenesis. Exp Oncol 39: 98-105.

109. Xiao Y, Zhang S, Tong H, Shi S (2018) Comprehensive evaluation of the role of soy and isoflavone supplementation in humans and animals over the past two decades. Phytother Res 32: 384-394.

110. Zhang L, Wei Y, Zhang J (2014) Novel Mechanisms of anticancer activities of green tea component Epigallocatechin- 3-gallate. Anticancer Agents Med Chem 14: 779-786.

111. Steele VE, Kelloff GJ, Balentine D, Boone CW, Mehta R, et al. (2000) Comparative chemopreventive mechanisms of green tea, black tea and selected polyphenol extract measured by in vitro bioassays. Carcinogenesis 21: 6367.

112. Dybkowska E, Sadowska A, Świderski F, Rakowska R, Wysocka K (2018) The occurrence of resveratrol in foodstuffs and its potential for supporting cancer prevention and treatment. A Review. Rocz Panstw Zakl Hig 69: 5-14.

113. Salehi B, Mishra AP, Nigam M, Sener B, Kilic M (2018) Resveratrol: A double-edged sword in health benefits. Biomedicines 6: E91.

114. Doello K, Ortiz R, Alvarez PJ, Melguizo C, Cabeza L, et al. (2018) Latest in Vitro and in Vivo assay, clinical trials and patents in cancer treatment using curcumin: A literature review. Nutr Cancer 70: 569-578.

115. Nagini S, Palitti F, Natarajan AT (2015) Chemopreventive potential of chlorophyllin: A review of the mechanisms of action and molecular targets. Nutr Cancer 67: 203-211.

116. Aiyer HS, Warri AM, Woode DR, Hilakivi Clarke L, Clarke R (2012) Influence of berry polyphenols on receptor signaling and cell-death pathways: Implications for breast cancer prevention. J Agric Food Chem 60: 5693-5708.

117. Jeong H, Phan ANH, Choi JW (2017) Anti-cancer effects of polyphenolic compounds in epidermal growth factor 
receptor tyrosine kinase inhibitor-resistant non-small cell lung cancer. Pharmacogn Mag 13: 595-599.

118. Chun KS, Kundu J, Chae IG, Kundu JK (2014) Carnosol: A phenolic diterpene with cancer chemopreventive potential. J Cancer Prev 19: 103-110.

119. Kunzmann AT, Coleman HG, Huang WY, Cantwell MM, Kitahara CM (2016) Fruit and vegetable intakes and risk of colorectal cancer and incident and recurrent adenomas in the plco cancer screening trial. Int J Cancer 138: 18511861.

120. Rath M, Pauling L (1992) Plasmin-induced proteolysis and the role of apoprotein(a), lysine, and synthetic lysine analogs. J Orthomol Med 7: 17-23.

121. Sugimura $T$ (1985) Carcenogenicity of mutagenic heterocyclic amines formed during the cooking process. Mutat Res 150: 33-41.

122. Laake I, Carlsen MH, Pedersen JI, Weiderpass E, Selmer $\mathrm{R}$, et al. (2013) Intake of trans fatty acids from partially hydrogenated vegetable and fish oils and ruminant fat in relation to cancer risk. Int J Cancer 132: 1389-1403.

123. Qurrat-ul-Ain, Khan SA (2015) Artificial sweeteners: Safe or unsafe? J Pak Med Assoc 65: 225-227.

124. Marinovich M, Galli CL, Bosetti C, Gallus S, La Vecchia C (2013) Aspartame, low-calorie sweeteners and disease: Regulatory safety and epidemiological issues. Food Chem Toxicol 60: 109-115.

125. Lebovitz AD (2009) Artificial sweeteners: Options for chronic kidney disease patients. Journal of Renal Nutrition 19: e15-e18.

126. (2013) Rules and Regulations. Federal Register 78.

127. Hocman G (1988) Chemoprevention of cancer: Phenolic antioxidant (BHT, BHA). Int J Biochem 20: 639-651.

128. Kurokawa Y, Maekawa A, Takahashi M, Hayash Y (1990) Toxicity and carcinogenicity of potassium bromate--a new renal carcinogen. Environ Health Perspect 87: 309-335.

129. https://www.cancer.gov/about-cancer/causes-prevention/ risk/myths/fluoridated-water-fact-sheet.

130. Eveliens (2017) Seven deadly synthetic food dyes.

131. Bassil KL, Vakil C, Sanborn M, Cole DC, Kaur JS, et al. (2007) Cancer health effects of pesticides: Systematic review. Can Fam Physician 53: 1704-1711.

132. Pesticide-induced diseases database. Beyond Pesticides.

133. Alavanja MC, Hofmann JN, Lynch CF, Hines CJ, Barry KH, et al. (2014) Non-hodgkin lymphoma risk and insecticide, fungicide and fumigant use in the agricultural health study. PLoS One 9: e109332.

134. Ma ES (2017) recurrent cytogenetic abnormalities in nonhodgkin's lymphoma and chronic lymphocytic leukemia. Methods Mol Biol 1541: 279-293.

135. Chiu BC, Dave BJ, Blair A, Gapstur SM, Zahm SH, et al. (2006) Agricultural pesticide use and risk of $t(14 ; 18)$ defined subtypes of Non-hodgkin lymphoma. Blood 108: 1363-1369.

136. Guyton KZ, Loomis D, Grosse Y, El Ghissassi F, Benbrahim Tallaa L, et al. (2015) Carcinogenicity of tetrachlorvinphos, parathion, matathion, diazinon and glyphosate. Lancet Oncol 16: 490-491.

137. Chatterjee M, Ivanov V, Niedzwiecki A, Rath M (2017) Cell damaging effect of glyphosate - Are we ready for roundup. J Cell Med Nat Health.

138. Singletary K, Milner J (2008) Diet and autophagy and cancer: A review. Cancer Epidemiol Biomarkers Prev 17: $1596-1610$

139. Sheweita SA, Tilmisang AK (2003) Cancer and phase ii drug metabolizing enzymes. Curr Drug Metab 4: 45-58.

140. Jana S, Mandlekar S (2009) Role of phase II drug metabolizing enzymes in cancer chemoprevention. Curr Drug Metab 10: 595-616.

141. Netke SP, Roomi MW, Ivanov V, Niedzwiecki $A$, Rath $M$ (2003) A specific combination of ascorbic acid, lysine, prolinę and epigallocatechin gallate inhibits proliferation and extracellular matrix invasion of various human cancer cell lines. Research Communications in Pharmacology and Toxicology, Emerging Drugs 2: IV37-IV50.

142. Niedzwiecki A, Roomi MW, Kalinovsky T, Rath M (2010) Micronutrient synergy--A new tool in effective control of metastasis and other key mechanisms of cancer. Cancer Metastasis Rev 29: 529-542.

143. Roomi MW, Bhanap B, Niedzwiecki A, Rath M (2016) Apoptosis of human fibrosarcoma cells HT-1080 triggered by a novel nutrient mixture via induction of caspases. Sarcoma Res Int 3: 1036.

144. Roomi MW, Shanker N, Niedzwiecki A, Rath M (2015) Induction of apoptosis in the human prostate cancer cell line DU-145 by a novel micronutrient formulation. Open Journal of Apoptosis 4: 11-21.

145. Roomi MW, Bhanap B, Niedzwiecki A, Rath M (2018) A novel nutrient mixture induces apoptosis in human ovarian and cervical cancer cells. J Cervical Cancer Res 2: 10-17.

146. Harakeh S, Azar R, Azhar E, Damanhouri GA, Assidi M, et al. (2015) Specific nutrient combination effects on tax, NF-kB and MMP-9 in human T-cell lymphotropic virus-1 positive malignant T-lymphocytes. BMC Cancer 15: S2.

147. Harakeh S, Abou Khouzam R, Damanhouri GA, Al Hejin A, Kumosani T, et al. (2014) Effects of nutrients on matrix metalloproteinases in human $t$ lymphotropic virus Type1 positive and negative malignant T-lymphocytes. Int $\mathrm{J}$ Oncol 45: 2159-2166.

148. Roomi WM, Kalinovsky T, Rath M, Niedzwiecki A (2016) Nutraceuticals in cancer prevention. Gupta RC, Nutraceuticals - Efficacy, Safety and Toxicity. Academic Press, 525 BStreet, Ste.1800, San Diego, CA 92102, USA, 135-144. 